\title{
Comparative analysis for estimating production costs
}

\author{
Carmen-Elena Stoenoiu ${ }^{1, *}$, Ciprian Cristea $^{2}$ \\ 1,2 Technical University of Cluj-Napoca, Department Electrical Machines and Drives, Cluj-Napoca, România
}

\begin{abstract}
The analysis of the cost of production is a complex problem, being very useful in the planning and control process as well as in production and sales. In this study, this was done using three methods: accounting analysis, high-low and regression analysis that allowed cost elements to be identified through a cost equation that can be used in planning and control analysis or in sales activity. At the same time, the evolution of the cost elements was achieved using two estimates used by the accounting method. The High-Low method allowed the determination of the minimum and maximum activity level at one year's level, which was then analyzed through the company's available activity range. The multivariate regression analysis determined the analysis of the obtained model, being linear, thus establishing the production line.
\end{abstract}

\section{INTRODUCTION}

The increasing complexity of economic activity as well as its variety are increasingly requiring an effective management of resources. In this context, cost management tools play an important role because they allow costs to be aligned to the strategy of the company [1], [2]. Because in the economic activity the behaviour of production costs is different, managers are often put in the position to make estimates based on past or present information provided by financial or management accounting, through financial reports or through dashboard [3], [4].

The decision or the managerial act depends increasingly on the information provided by the financial-accounting activity, the quality and the speed of the information, the way it is processed and transformed into clear, pertinent and complete information [5]. The future of a company is often dependent on the speed with which it manages to make decisions, respectively to adapt to the concrete conditions existing on the market. So, most of the informational system plays an essential role because it allows to know the costs, how they change to the volume of production, allowing component identification, fluctuation observation and the successful completion of the managerial act [6], [7].

Cost management is a widely discussed topic in the literature as it is considered to provide support in the decision-making process [8], [9], allows the development of performance planning and management systems [10], [11], advising managers on the formulation and implementation of corporate strategy [12], [13], and when flexible they represent a resource to create new scenarios within the organization [14], [15]. Fixed costs, typically linear, are those expected costs because they are already engaged (in progress) and can not be changed in a short period of time [16]. Variable costs, in turn, are fluctuating (direct material costs, direct wages, etc.), including various aspects related to the characteristics of manufactured products [17], [18]. Variable cost tracking is useful because it allows the manager to know the costs which can be manipulated and controlled [19]. In the literature, it is considered that when fixed costs have a significant weight in total costs, managers need to find solutions for sales growth [20]. The way of tracking the information provided by accounting and subsequently encompassing the financial reports is also debated by various specialists [21].

Since managers make many decisions through production costs, precision is important because a small distortion can have a major influence on the firm's profit [22]-[24].

In this paper, an analysis of production costs was made, starting from the information provided by the accounting. The goal was to exemplify through three different ways (accounting analysis, High-Low and regression analysis) the calculation, estimation and cost analysis based on the information from financial accounting.

\section{MATERIALS AND METHODS}

Three methods were used to analyze production costs: accounting analysis (AA), High-Low method (HLM) and regression analysis (RA), starting from the idea that small and medium enterprises do not always have sufficient financial resources to acquire performance software capable of providing detailed cost analyses.

The information on the production costs is in the accounting records of any company, irrespective of its size, it only requires processing, and i.e. their take over from the balance of monthly checking of the accounts, 
the distribution by cost types and then the summation of each type of cost. The starting point was the identification and grouping of all production costs in a company's accounting records, according to Table 1, by type of costs (fixed and variable).

Table 1. Correspondence costs from financial accounting into managerial accounting.

\begin{tabular}{|c|c|}
\hline Production costs & Accounts groups (Account) \\
\hline \multicolumn{2}{|l|}{ 1. Fixed costs, from which: } \\
\hline $\begin{array}{l}\text { - Utilities (electrical energy, } \\
\text { water, telephone, gas energy, } \\
\text { etc.) }\end{array}$ & $\begin{array}{l}\text { 60. Stock expenditure (acc. } 605) \text {; } \\
\text { 62. Expenses with other service } \\
\text { provided by third parties (acc. } 626 \text { ). }\end{array}$ \\
\hline $\begin{array}{l}\text { - Services performed by third } \\
\text { parties (rent, maintenance and } \\
\text { repairs, insurance, studies and } \\
\text { research) }\end{array}$ & $\begin{array}{l}\text { 61. Expenditure related to third- } \\
\text { party services (acc. } 611 \div 614 \text { ) }\end{array}$ \\
\hline $\begin{array}{l}\text { - Fixed asset depreciation } \\
\text { (equipment, machinery, } \\
\text { buildings, means of transport, } \\
\text { etc.) }\end{array}$ & $\begin{array}{l}\text { 68. Expenses, provisions and } \\
\text { adjustments for depreciation or loss } \\
\text { of value (acc. } 6811 \text { ) }\end{array}$ \\
\hline \multicolumn{2}{|l|}{ 2. Variable costs, from which: } \\
\hline - Consumables & $\begin{array}{l}\text { 60. Stock expenses (acc. } 601 \div \\
604,608,609)\end{array}$ \\
\hline $\begin{array}{l}\text { - Assembly / processing } \\
\text { salaries }\end{array}$ & 64. Staff costs (acc. 641-645) \\
\hline
\end{tabular}

The equations used was defined by (1-6):

$$
\begin{gathered}
P C=F C+V C \\
F C=U+T P S+F A \\
V C=M+S \\
E P C=C V I \\
E C=(M A C-M C) /(\operatorname{Max} Q-\operatorname{Min} Q) \\
T C=F C+(U V C \times Q)
\end{gathered}
$$

Where: PC - production cost; FC - fixed cost; VC variable cost; U - utilities; TPC - third party services; FA - fixed assets; $\mathrm{M}$ - materials; $\mathrm{S}$ - salary; EPC estimated poor cost; CV - cost variation; AV - activity variation; EC - estimated cost; MAC - maximum activity costs; MC - minimum costs; MaxQ - maximum quantity; MinQ - minimum quantity; TC - total cost; UVC - unit variable cost; $\mathrm{Q}$ - quantity.

The AA is based on the use of the professional judgment of the analyst and involves the grouping of costs in fixed and variable, and then the establishment of the unitary cost of the activity. This analysis seeks to know: what are the possible variations, in the unit cost of production, when changing the quantity produced. The way in which the calculations were made are presented in Table 2, using the month of May as the reference month.

Because of the complex nature of these costs, sometimes the assignment is difficult, therefore two estimates for accounting analysis were used in this study:

The first estimate involves the delimitation of the production costs in fixed and variable ones, considering that the specificity of the activity allows their clear delimitation (Table 3).

Table 2. Production costs related to May [RON].

\begin{tabular}{|l|r|}
\hline \multicolumn{1}{|c|}{ Cost elements } & \multicolumn{1}{|c|}{ Value } \\
\hline Quantity & 1,950 \\
\hline Production costs, from which: & 115,900 \\
\hline - Consumables (C) & 83,100 \\
\hline - Assembly / processing salaries (AS) & 7,100 \\
\hline - Utilities (U) & 18,000 \\
\hline - Services performed by third parties (SPTP) & 50,900 \\
\hline - Fixed asset depreciation (FAD) & 275,000 \\
\hline Total
\end{tabular}

The second estimate of fixed and variable production costs takes into account that some of the utility costs change with the volume of production and therefore cannot be considered totally fixed, the appreciation being $50 \%$ fixed and $50 \%$ as variables (Table 4 ).

After identifying costs by cost type for each month, the data was centralized to analyze: fluctuations that exist from one month to the next at fixed cost, variable cost and total cost, physical output level (quantitative) and fixed unit costs and variables. It was considered that the company's business is not constant, with some changes from one month to the next. Subsequently data was centralized at the level of a calendar year.

It was considered that the analyzed activity evolved linearly over twelve months and what is outside this behavior is an exception that needs to be identified and analyzed separately.

The HLM was used to see the variation of production cost components (fixed and variable) and their level at various work volume changes. The High-Low method allows us to observe the maximum and minimum points, that is, the maximum and minimum level of activity performed. Starting from (4) we obtained (5), which allows us to determine the high and low cost variables through the High-Low method.

The RA was based on the following assumptions: the independent variable is quantitative or dichotomic (in this variable study is the quantity of products obtained in one year); the variable is measured without error; the independent variable has a nonzero variant; there is no multicollinearity; the mean value of the variable e (error) is zero for any set of values of the independent variables; each independent variable is uncorrelated with the variable $\varepsilon$; the variant of $\varepsilon$ is constant-homoscedasticity; for any two observations, the errors are uncorrelated; for any values of the independent variables, $\varepsilon$ is normally distributed.

Taking $\left(\mathrm{x}_{\mathrm{i}}, \mathrm{y}_{\mathrm{i}}\right)$, as a set of data, it results a function $\mathrm{f}$ : $\mathrm{R} \rightarrow \mathrm{R}$. The variable $\varepsilon$ was defined by (7):

$$
e_{i}=y_{i}-f\left(x_{i}\right)=y_{i}-\dot{y}_{i}
$$

Where: $\mathrm{i}=1 \div \mathrm{m}, \mathrm{m}$, is called the residual variable, and the values of this variable are called residual values.

To solve it, we need the absolute value of the residual values, but to work with expressions we use their squares. The sum of squares of residual values is called 
the residual quadratic sum. By replacing "y" with its value, the relationship becomes (8):

$$
\Sigma\left(\mathrm{y}_{\mathrm{i}}-\mathrm{a}-\mathrm{bx}_{\mathrm{i}}\right) 2=\text { minimum }
$$

Deriving in relation to "a" and "b" by canceling the partial derivatives, the system of normal equations is obtained (9-10):

$$
\begin{gathered}
\text { na }+ \text { b } \Sigma \mathrm{x}_{\mathrm{i}}=\Sigma \mathrm{y}_{\mathrm{i}} \\
\mathrm{a} \Sigma \mathrm{x}_{\mathrm{i}}+\mathrm{b} \Sigma \mathrm{x}_{\mathrm{i}}=\Sigma \mathrm{x}_{\mathrm{i}} \mathrm{y}_{\mathrm{i}}
\end{gathered}
$$

Where: $\mathrm{n}$ - the number of units observed, ie the number of pairs $(x, y)$.

It follows that $y=a+b x$, which means that the regression right passes through the mean point $(\mathrm{x}, \mathrm{y})$. By solving the system of normal equations, parameters "a" and "b" are obtained. The coefficient $a$, which can take both positive and negative values, is ordered at origin, that is, the value of $y$ when $x$ is equal to zero. The coefficient $b$ is referred to as the regression coefficient which shows the extent to which the dependent characteristic varies when the independent feature changes with a unit.

\section{RESULTS AND DISCUSSION}

Through the AA, fixed costs (FC) and variable costs (VC) were calculated using the two estimates (cases A and B), which are presented in Table 3.

Table 3. Estimated production costs for May through accounting analysis [RON].

\begin{tabular}{|l|r|r|l|r|r|}
\hline $\begin{array}{c}\text { Cost } \\
\text { elements }\end{array}$ & Case A & Case B & \multicolumn{1}{c|}{$\begin{array}{c}\text { Cost } \\
\text { elements }\end{array}$} & Case A & Case B \\
\hline 1. FC & 76,000 & 72,450 & \multicolumn{1}{|c|}{$2 . \mathrm{VC}$} & 199,000 & 202,550 \\
\hline - U & 7,100 & 3,550 & $-\mathrm{U}$ & & 3,550 \\
\hline - SPTP & 18,000 & 18,000 & $-\mathrm{C}$ & 115,900 & 115,900 \\
\hline \multirow{2}{*}{ FAD } & 50,900 & 50,900 & $-\mathrm{AS}$ & 83,100 & 83,100 \\
\cline { 3 - 6 } & & & Q & 1,950 & 1,950 \\
\hline
\end{tabular}

Table 4. Distribution of monthly production costs [RON].

\begin{tabular}{|l|c|c|c|c|c|}
\hline \multirow{2}{*}{ Month } & \multirow{2}{*}{$\begin{array}{c}\text { Quantity } \\
{[\text { Pcs.] }}\end{array}$} & \multicolumn{2}{|c|}{ Case A } & \multicolumn{2}{c|}{ Case B } \\
\cline { 3 - 6 } & 800 & 76,000 & 104,000 & 72,450 & 107,550 \\
\hline January & 1,100 & 76,000 & 114,000 & 72,450 & 117,550 \\
\hline February & 1,250 & 76,000 & 134,000 & 72,450 & 137,550 \\
\hline March & 1,650 & 76,000 & 169,000 & 72,450 & 172,550 \\
\hline April & 1,950 & 76,000 & 199,000 & 72,450 & 202,550 \\
\hline May & 2,250 & 76,000 & 209,000 & 72,450 & 212,550 \\
\hline June & 2,900 & 76,000 & 339,000 & 72,450 & 342,550 \\
\hline July & 2,750 & 76,000 & 299,000 & 72,450 & 302,550 \\
\hline August & 2,450 & 76,000 & 224,000 & 72,450 & 227,550 \\
\hline September & 1,200 & 76,000 & 132,000 & 72,450 & 135,550 \\
\hline October & 1,000 & 76,000 & 104,000 & 72,450 & 107,550 \\
\hline November & 1,000 & 72,450 & 77,550 \\
\hline December & 500 & 76,000 & 74,000 & 72,400 \\
\hline Total & 20,000 & 912,000 & $2,101,000$ & 869,400 & $2,143,600$ \\
\hline
\end{tabular}

From the analysis of Tables 3 it can be noticed that the different estimation of a cost of production component (utilities) led to the obtaining of different values of the unitary and total variable cost and of the total fixed cost.

The process used for May continued for all the months of the year, thus obtaining a monthly cost of production, as shown in Table 4.

The evolution of fixed and variable costs using the two estimates at the level of the 12 months is shown in Fig. 1 and Fig. 2.

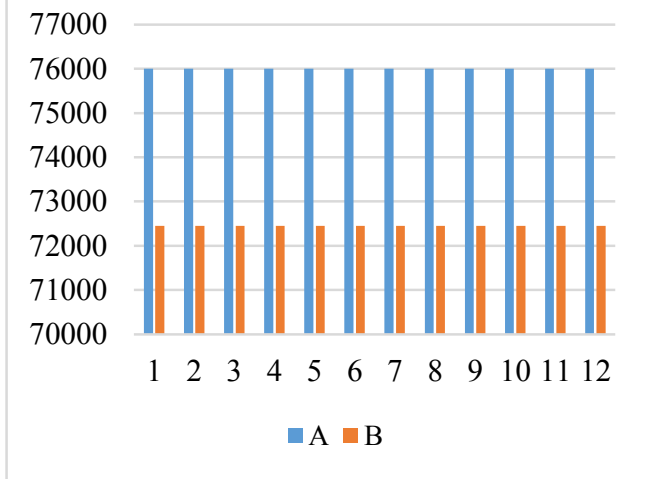

Fig. 1. Evolution of the Fixed costs

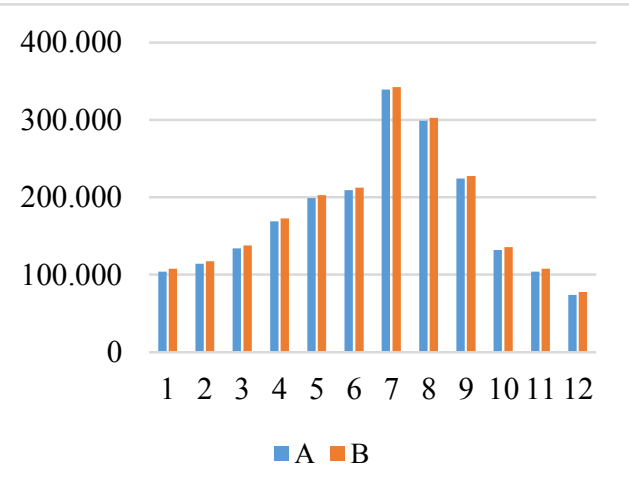

Fig. 2. Evolution of the Variable costs

From the analysis of Fig. 1 and Fig. 2 it can be noticed that the evolution of the fixed and variable costs at the level of the two production cost estimates (Cases A and B) is slightly modified. The evolution of fixed and variable costs per unit using the two estimates at the level of the 12 months is presented in Fig. 3:

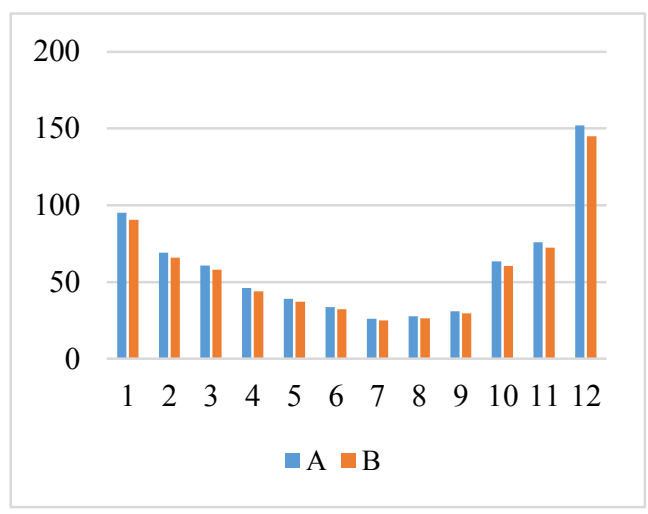

Fig. 3. Evolution of the Fixed costs per unit 


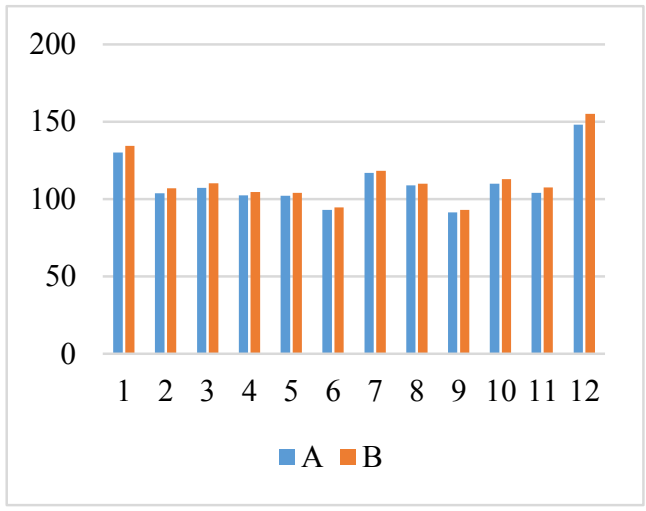

Fig. 4. Evolution of the Variable costs per unit

The AA allows us to observe the minimum level of unitary cost versus the physical volume of production (Fig. 4).

From the AA using the two estimates presented in Fig. 5 we can see that the evolution of the unitary cost variables, according to the quantity shows a small difference between the two estimates (Cases A and B).

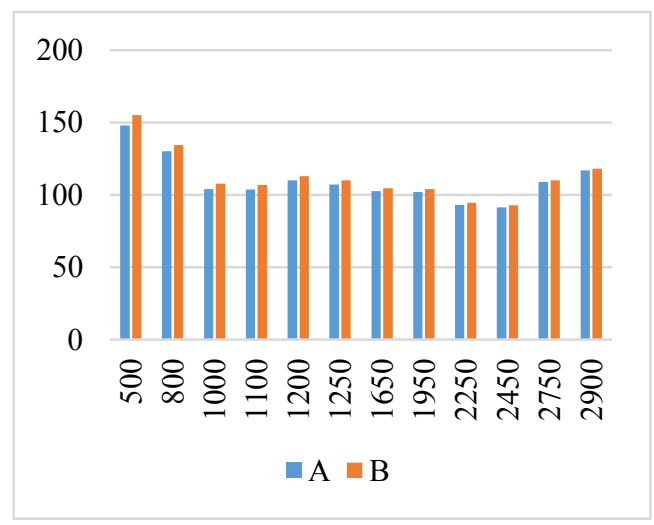

Fig. 5. Evolution of the unit variable costs according to the quantity

Since the distribution of total costs in fixed and variable is sometimes subjective on the one hand due to their variation over time and, on the other hand, due to the way these costs are accepted or understood, the use of this method does not always provide us with surety about costing.

Using the HLM, it was possible to estimate the level of the variables in the production cost component to the lowest level activity (LLA) or the highest level of activity (HLM), as shown in Table 5.

Table 5. Estimated High-Low method [RON]

\begin{tabular}{|l|c|c|}
\hline \multicolumn{1}{|c|}{ Indicators } & LLA & HLA \\
\hline Total cost & $131,208.33$ & $396,208.33$ \\
\hline Variable cost estimate & $55,208.33$ & $320,208.33$ \\
\hline Fixed Cost Estimate & 76,000 & 76,000 \\
\hline
\end{tabular}

The HLM is useful after the managers have set the possible production range that can be achieved taking into account the production capacity. According to the example taken in the study, if at $50 \%$ we are profit and not loss and this means producing 500 pieces using a production range between $500-3,200$ pieces, it means we have $100 \%$ at maximum. Through this analysis we can delimit both the degree of loading and the monthly production capacity recorded at the entity level, ie the position against the minimum or the maximum taking into account the technical level, as well as the minimum acceptable quantities for the company to make profit.

For the RA, the following variables listed in Table 6 were taken into account.

Table 6. Annual state

\begin{tabular}{|l|c|c|}
\hline Month & $\begin{array}{c}\text { Quantity } \\
{[\text { Pcs.] }}\end{array}$ & $\begin{array}{c}\text { Total cost production } \\
{[\text { RON] }}\end{array}$ \\
\hline January & 800 & 180,000 \\
\hline February & 1,100 & 190,000 \\
\hline March & 1,250 & 210,000 \\
\hline April & 1,650 & 245,000 \\
\hline May & 1,950 & 275,000 \\
\hline June & 2,250 & 285,000 \\
\hline July & 2,900 & 415,000 \\
\hline August & 2,750 & 375,000 \\
\hline September & 2,450 & 300,000 \\
\hline October & 1,200 & 208,000 \\
\hline November & 1,000 & 180,000 \\
\hline December & 500 & 150,000 \\
\hline
\end{tabular}

Table 7 presents statistical indicators computed through regression analysis.

Table 7. Statistical indicators

\begin{tabular}{|l|r|}
\hline \multicolumn{1}{|c|}{ Statistic } & \multicolumn{1}{c|}{ Value } \\
\hline Multiple R & 0.97 \\
\hline Multiple $\mathrm{R}^{2}$ & 0.95 \\
\hline Adjusted $\mathrm{R}^{2}$ & 0.94 \\
\hline $\mathrm{F}(1,10)$ & 179.93 \\
\hline $\mathrm{p}$ & $1.02 \times 10^{-7}$ \\
\hline Std.Err. of Estimate & $19,735.39$ \\
\hline
\end{tabular}

The RA led to the identification of unit variable cost and total fixed cost when the total cost of production and the quantity for each month of the year are known, as shown in Table 8.

Table 8. Regression analysis

\begin{tabular}{|c|c|}
\hline $\mathbf{N = 1 2}$ & $\mathbf{B}$ \\
\hline Intercept (a) & $85,930.01$ \\
\hline Quantity (b) & 100.09 \\
\hline
\end{tabular}

From the analysis of Table 8 we can see the value of the regression analysis for the fixed cost and for the unitary cost.

Following the calculations of the total fixed cost and the unitary cost of each of the 3 methods taken in the study, the equation of production cost was obtained, as shown in Table 9:

Table 9. Equation of production cost

\begin{tabular}{|c|c|c|}
\hline Methods & General equation & Equation of production cost \\
\hline AA (Case A) & \multirow{4}{*}{$\mathrm{Cp}=\mathrm{CF}+\mathrm{Cvu}_{\mathrm{u}} \times \mathrm{Q}$} & $\mathrm{Cp}=76,000+106.11 \times \mathrm{Q}$ \\
\hline AA (Case B) & & $\mathrm{Cp}=72,450+108.26 \times \mathrm{Q}$ \\
\hline HLM & & $\mathrm{Cp}=76,000+110.41 \times \mathrm{Q}$ \\
\hline $\mathrm{RA}$ & & $\mathrm{Cp}=85,930.01+100.09 \times \mathrm{Q}$ \\
\hline
\end{tabular}


For each total value of your monthly $(\mathrm{Q})$ production, the total cost of production also recorded a different value. The unitary variable cost, using the AA, was obtained by means of the simple arithmetic mean, both for case A and case B. The unit-variable cost of HLM was obtained by reporting the total variable cost to the quantity (min. or max.) and the RA mathematically calculated this cost based on the monthly quantity and total cost of production. Analysing the four equations there are some differences from the initial situation, which are presented in Table 10.

Table 10. Comparison between the initial cost of production and the values obtained by using the methods [RON]

\begin{tabular}{|c|c|c|r|r|r|}
\hline \multirow{2}{*}{ Month } & CTPI & CTPACA & \multicolumn{1}{c|}{$\begin{array}{c}\text { Dif. } \\
\text { CTPACA }\end{array}$} & CTPACB & \multicolumn{1}{c|}{$\begin{array}{c}\text { Dif. } \\
\text { CTPACB }\end{array}$} \\
\hline 0 & 1 & \multicolumn{1}{c|}{2} & \multicolumn{1}{c|}{$3=2-1$} & \multicolumn{1}{c|}{4} & $5=4-1$ \\
\hline 01 & 180,000 & $160,888.88$ & $-19,111.12$ & $159,060.08$ & $-20,939.92$ \\
\hline 02 & 190,000 & $192,722.21$ & $2,722.21$ & $191,538.86$ & $1,538.86$ \\
\hline 03 & 210,000 & $208,638.88$ & $-1,361.13$ & $207,778.25$ & $-2,221.75$ \\
\hline 04 & 245,000 & $251,083.32$ & $6,083.32$ & $251,083.29$ & $6,083.29$ \\
\hline 05 & 275,000 & $282,916.65$ & $7,916.65$ & $283,562.07$ & $8,562.07$ \\
\hline 06 & 285,000 & $314,749.98$ & $29,749.98$ & $316,040.85$ & $31,040.85$ \\
\hline 07 & 415,000 & $383,722.19$ & $-31,277.81$ & $386,411.54$ & $-28,588.46$ \\
\hline 08 & 375,000 & $367,805.53$ & $-7,194.48$ & $370,172.15$ & $-4,827.85$ \\
\hline 09 & 300,000 & $335,972.20$ & $35,972.20$ & $337,693.37$ & $37,693.37$ \\
\hline 10 & 208,000 & $203,333.32$ & $-4,666.68$ & $202,365.12$ & $-5,634.88$ \\
\hline 11 & 180,000 & $182,111.10$ & $2,111.10$ & $180,712.60$ & 712.60 \\
\hline 12 & 150,000 & $129,055.55$ & $-20,944.45$ & $126,581.30$ & $-23,418.70$ \\
\hline Total & $3,013,000$ & $3,012,999.78$ & -0.22 & $3,012,999.48$ & -0.52 \\
\hline
\end{tabular}

\begin{tabular}{|c|c|c|c|c|}
\hline Month & CTPMHL & Dif. CTPMHL & CTPAR & Dif. CTPAR \\
\hline 0 & 6 & $7=6-1$ & $\overline{8}$ & $9=8-1$ \\
\hline 01 & $164,328.00$ & $-15,672.00$ & $166,002.01$ & $-13,997.99$ \\
\hline 02 & $197,451.00$ & $7,451.00$ & $196,029.01$ & $6,029.01$ \\
\hline 03 & $214,012.50$ & $4,012.50$ & $211,042.51$ & $1,042.51$ \\
\hline 04 & $258,176.50$ & $13,176.50$ & $251,078.51$ & $6,078.51$ \\
\hline 05 & $291,299.50$ & $16,299.50$ & $281,105.51$ & $6,105.51$ \\
\hline 06 & $324,422.50$ & $39,422.50$ & $311,132.51$ & $6,132.51$ \\
\hline 07 & $396,189.00$ & $-18,811.00$ & $376,191.01$ & $-38,808.99$ \\
\hline 08 & $379,627.50$ & $4,627.50$ & $361,177.51$ & $-13,822.49$ \\
\hline 09 & $346,504.50$ & $46,504.50$ & $331,150.51$ & $31,150.51$ \\
\hline 10 & $208,492.00$ & 492.00 & $206,038.01$ & $-1,961.99$ \\
\hline 11 & $186,410.00$ & 641,000 & $186,020.01$ & $6,020.01$ \\
\hline 12 & $131,205.00$ & $-18,795.00$ & $135,975.01$ & $-14,024.99$ \\
\hline Total & $3,098,118.00$ & $85,118.00$ & $3,012,942.12$ & -57.88 \\
\hline \multicolumn{5}{|c|}{$\begin{array}{l}\text { CTPI - total initial production cost; CTPACA - total cost of production } \\
\text { obtained through the accounting analysis variant (a); CTPACB - total } \\
\text { cost of production obtained through the accounting analysis variant (b); } \\
\text { CTPMHL - total cost of production obtained by the High-Low method; } \\
\text { CTPAR - total production cost obtained by regression analysis. }\end{array}$} \\
\hline
\end{tabular}

Table 10 shows that the total differences recorded for the accounting analysis (Cases A and B) per total year are very small (to be neglected), which are followed (as order of magnitude) by the RA. HLA does not help us estimate the cost of production because the difference is very high. The strong point of the RA is that this and if it is not known, the values of the total fixed and unitary cost can establish the equation of the total cost of production, thus establishing the relationship between the fixed cost, the variable cost and the quantity, very useful for managers in the decision-making process as it allows the sale price to be determined and participation in negotiations with potential customers before the production is in stock, meaning to know in detail all the cost elements.

\section{CONCLUSIONS}

The AA made it possible to know the production costs and their evolution. This analysis is useful for managers in small and medium businesses because it allows to determine the quantity of products that can be produced at the lowest cost and to adapt it to the economic conditions existing on the market. Using billboards that take account of accounting information, managers can get to know these production costs and track them both on a total and per product basis. Thus, they can establish or adjust their production volume and, implicitly, the sales price in terms of profitability, taking into account the production costs, the changes that occur at the cost level of both the material component and the wage component.

HLM is useful because it allows managers to know where the costs are high and small, and by delimiting a possible production range, depending on the capacity of the firm, to know the variance of these costs within that range. It is an analysis of the past but which provides enough information, ie it signals the levels of activity that have been recorded and what influences they have determined at each cost level. Future decisions can be improved by knowing the past, the disturbing factors and the concrete production possibilities.

The strong point of the RA is that this analysis can also be performed when the values of the fixed and total fixed cost are not known. Starting from the total production cost of the previous year and from the production quantity and considering that next year the activity will remain at least constant, the equation of the total production cost can determined. By establishing the link between the fixed cost, variable cost and quantity, this will help managers in the decision making process, while allowing cost planning and control.

Because often the costs of tracking and calculating the cost elements required for an analysis involve additional costs, and firms are often required to make cost cuts, using this comparative analysis companies can calculate and observe differences in production cost as a result of changes in the quantity produced. Although the analysis has taken into account only the production costs (without general administrative costs), we consider that the analysis is useful because it allows the delimitation of those costs that represent the largest share in the total cost.

\section{References}

1. W.M. Baker, The missing element in cost management: Competitive target costing, Ind. Manag., 37 (2), 29-32 (1995).

2. R. Cooper, R Slagmulder, Develop profitable new products with target costing, MIT Sloan Manag. Rev., 40 (4), $23-34$ (1999).

3. A.D. Jr. Chandler, H. Daems, Administrative coordination, allocation and monitoring: a 
comparative analysis of the emergence of accounting and organization in the USA and Europe, Acc. Org. and Soc., 4, 3-20 (1979).

4. P. Skærbæk, K. Tryggestad, The role of accounting devices in performing corporate strategy, Acc., Org. and Soc., 35 (1), 108-124 (2010).

5. S.Y. Collin, T. Tagesson, A. Anderson, J. Cato, $\mathrm{K}$. Hansson, Explaining the choice of accounting standards in municipal corporations. Positive accounting theory and institutional theory as competitive or concurrent theories, Critic. Persp. on Acc., 20 (2), 141-174 (2009).

6. Z. Toth, The current role of accounting information systems, Club of Economics in Miskolc' TMP, 8 (1), 91-95 (2012).

7. Y.W. Kim, S.C. Kim, Cost analysis of information technology-assisted quality inspection using activity-based costing, Constr. Manag. and Ec., 163-172 (2011).

8. H.U. Kupper, Investment-based cost accounting as a fundamental basis of decision-oriented management accounting, Abacus, 45 (2), 249274 (2009).

9. J. Innes, F. Mitchell, D. Sinclair, Activity-based costing in the U.K.'s largest companies: a comparison of 1994 and 1999 survey results, Manag. Acc. Res., 11 (3), 349-362 (2000).

10. D.J. Stockton, J.E. Middle, An aproach to improving cost estimating, Int. J. Prod. Res., 20 (6), 741-751 (1982).

11. C.D.A. Wanderley, J. Cullen, $A$ case of management accounting change: the political and social dynamics, Rev. Contab. \& Fin., 23 (60), 161-172 (2012).

12. C. Horngren, S.M. Datar, M. Rajan, Cost accounting, a managerial emphasis, Prentice Hall, 14-th edition, ISBN: 9780132109178, (2006).

13. L.O. Obokoh, G. Goldman, Infrastructure deficiency and the performance of small-and medium-sized enterprises in Nigeria's Liberalised Economy, Acta Commercii, 16 (1), 339 (2016).

14. B. Nixon, J. Burns, The paradox of strategic management accounting, Manag. Acc. Res., 23 (4), 229-244 (2012).

15. R.H. Chenhall, F. Moers, The role of innovation in the evolution of management accounting and its integration into management control, Acc. Org. and Soc., 47, 1-13 (2015).

16. B.L. Miller, A.G. Buckman, Cost allocation and opportunity costs, Manag. Sc., 33 (5), 626639 (1987).

17. C. Sheu, L.J. Krajewski, A decision model for corrective maintenance management, Int. J. Prod. Res., 32, 1365-1382 (1993).

18. Z. Lin, D. Chang, Cost-tolerance analysis model based on a neural networks method, Int. J. Prod. Res., 40, 1429-1452 (2002).

19. B. Finch, S. Gavirneni, Confidence intervals for optimal selection among alternatives with stochastic variable costs, Int. J. of Prod. Res., 44 (20), 4329-4342 (2006).

20. P.H. Hsu, H.M. Wee, Discounting decision for enterprises with high fixed cost and low variable cost, Intl. Trans. in Op. Res., 13, 111124 (2006).

21. C. Pong, M. Falconer, Full costing versus variable costing: Does the choice still matter? An empirical exploration of UK manufacturing companies 1988-2002, The British Acc. Rev., 38, 131-148 (2006).

22. R. Cooper, R. Kaplan, How cost accounting distorts product costs, Manag. Acc., 69 (4), 20 28 (1988).

23. C. Drury, B.P. Osborne, M. Tayles, A survey of management accounting practices in U.K. manufacturing companies, London, U.K.: ACCA Publications (1993).

24. E. Shim, E.F. Sudit, How manufacturers price products, Manag. Acc., 76 (2), 37-39 (1995). 